\title{
Association Between Psychosocial Status and Orthodontic Treatment Needs in Indonesian High School Students
}

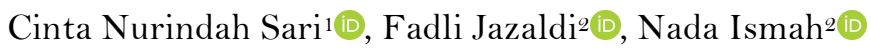

${ }^{1}$ Professional Program, Faculty of Dentistry, Universitas Indonesia, Jakarta, Indonesia.

${ }^{2}$ Department of Orthodontics, Faculty of Dentistry, Universitas Indonesia, Jakarta, Indonesia.

Author to whom correspondence should be addressed: Fadli Jazaldi, Department of Orthodontics, Faculty of Dentistry, Universitas Indonesia, Jl. Salemba Raya No. 4, Jakarta, Indonesia. Phone: +62 2131930270. E-mail: fadlijz@yahoo.co.id.

Academic Editor: Alessandro Leite Cavalcanti

Received: 03 March 2020 / Accepted: 08 June 2020 / Published: 22 June 2020

How to cite this article: Sari CN, Jazaldi F, Ismah N. Association between psychosocial status and orthodontic treatment needs in Indonesian high school students. Pesqui Bras Odontopediatria Clín Integr. 2020; $20:$ e5649. https://doi.org/10.1590/pboci.2020.115

\begin{abstract}
Objective: To determine whether psychosocial status is associated with orthodontic treatment needs in high school students using the Psychosocial Impact of the Dental Aesthetic Questionnaire (PIDAQ) and the Index of Orthodontic Need (IOTN). Material and Methods: This cross-sectional study comprised 95 adolescents, both genders, aged 15-17 years old. PIDAQ was used to assess psychosocial status. The IOTN Aesthetic Component (IOTN-AC) and the IOTN Dental Health Component (DHC) was used to assess treatment needs. Examination of the oral cavity was carried out with the help of the IOTN ruler by observing the MOCDO components: missing teeth, overjet, crossbite, displacement, and overbite. The Chisquare test was used to determine the association of psychosocial status and orthodontic treatment need. The reliability test was carried out by using Cronbach's Alpha test (0.978). Results: There was an association between psychosocial status and orthodontic treatment need based on the IOTN-AC $(p=0.001)$ and between psychosocial status and orthodontic treatment need based on the IOTN-DHC $(\mathrm{p}=0.140)$. Conclusion: There is an association between psychosocial status based on the PIDAQ and subjective orthodontic treatment need based on the IOTN-AC, but there is no association between psychosocial status based on the PIDAQ and objective orthodontic treatment need based on the IOTN-DHC in students of SMAN 27 Jakarta.
\end{abstract}

Keywords: Orthodontics; Dental Health Surveys; Index of Orthodontic Treatment Need. 


\section{Introduction}

A malocclusion refers to the relation of the teeth of two dental arches that deviate from their normal state [1]. According toWorld Health Organization (WHO), malocclusion is the third most frequent oral and dental problem after tooth caries and periodontal disease [2]. Individuals with malocclusion can be treated by an orthodontic intervention, which is a procedure that aims to correct irregularities of the teeth, so that health, oral function, appearance, and the social well-being of patients can be improved [1].

Teeth arrangement is an important component in facial aesthetics. Facial aesthetics have a great influence on self-confidence, which is one of the aspects of individual psychosocial conditions [3-5]. The concept of the psychosocial itself is a condition that involves psychological and social aspects. Psychosocial problems can be one of many factors leading an individual to seek orthodontic treatment $[5,6]$.

Teenagers tend to pay more attention to their appearance because in mid-adolescence, that is, in the age range of 15-17 years, individuals begin to interact with the opposite sex and also prioritize social relations and appearance [7]. Measuring instruments that can be used to determine the psychosocial status are the Global Assessment Scale (GAS) and the WHO-5 Well-Being Index [8,9]. The Psychosocial Impact of the Dental Aesthetic Questionnaire (PIDAQ) has been developed to measure psychosocial conditions associated with dental aesthetics. PIDAQ has been used widely and has been tested for validity and reliability in various samples $[6,10]$.

Orthodontic treatment need is assessed using various indices that aim to assist the dentist in determining the need for treatment. The Index of Orthodontic Need (IOTN) is one such index consisting of objective and subjective assessments. The IOTN is used to help determine the likely impact of malocclusion on an individual's dental health and psychosocial well-being. The IOTN consists of two components, an aesthetic component (i.e., assessment based on patients' perceptions of the appearance of the teeth) and a dental health component (i.e., an assessment based on the severity of a patient's malocclusion). The IOTN has gained international recognition as a method to assess orthodontic treatment need objectively and subjectively [4].

Based on previous research, there is a difference between the need for orthodontic treatment assessed by the dentist and the need for orthodontic treatment desired by the patient [11,12]. In general, dentists will prioritize function and occlusion of the patient in the assessment of orthodontic treatment need [13]. Previous research indicates that aesthetic improvements are the main goal of an individual in seeking orthodontic treatment [14]. Therefore, assessing the psychosocial condition of patients is necessary for the assessment of orthodontic treatment need so that the normative needs of the patients can be complemented [15].

Up to now, research on the association between the psychosocial status and the orthodontic treatment needs of adolescents has not been conducted in Indonesia. Therefore, research needs to be done to determine the association between the psychosocial status and orthodontic treatment needs of students' aged 15-17 in Jakarta, Indonesia.

\section{Material and Methods}

Study Design and Sample

This study is an analytical cross-sectional study consisting of 95 students of SMAN 27 Central Jakarta. The total sample size is in accordance with the result of the unpaired categorical comparative analytic calculation. This study was conducted between July and September 2018. The sampling technique used in this study was the multi-stage cluster sampling method. It began with the randomization of high school/equivalent in Kelurahan Johar Baru, followed by class randomization, and randomization of students in selected classes. 
The inclusion criteria for this study are students of SMAN 27 Johar Baru in 2018, aged 15-17 years old, who were willing to participate in the study and signed the informed consent form. As for the exclusion criteria, subjects who had already undergone orthodontic treatment were not included in the study. There were 118 students who completed the questionnaire, with a total of 23 students being excluded, because 10 students had undergone orthodontic treatment, 5 students are still on orthodontic treatment, and 8 students refused to get their teeth evaluated.

\section{Data Collection}

Subjects were instructed to complete a questionnaire consisting of an information sheet, an informed consent sheet, a self-identity sheet, an IOTN-AC sheet, and a PIDAQ sheet. The PIDAQ consists of 23 statements, which are grouped into four parts. The first part is dental self-confidence, the second part is social impact, the third part is aesthetic concern, and the fourth part is psychological impact. The PIDAQ uses a Likert scale ranging from 0 to 4 . The IOTN-AC sheet consists of an illustrated scale showing ten grades of dental aesthetics, ranging from grade 1, the most aesthetically pleasing, to grade 10, the least aesthetically pleasing. Grade 1 to Grade 4 represent "no need for treatment", Grade 5 to Grade 7 represent "borderline need for treatment", and Grade 8 to Grade 10 represent "great need for treatment."

The questionnaire was tested previously on 10 respondents $(10 \%$ of the sample size) to determine the validity and reliability. After completing the questionnaire, respondents got their orthodontic treatment needs evaluated by researchers based on the IOTN-DHC. Examination of the oral cavity was carried out with the help of the IOTN ruler by observing the MOCDO components: Missing teeth, Overjet, Crossbite, Displacement, and Overbite.

\section{Data Analysis}

The Statistical Package for Social Sciences (SPSS) software, version 20 (IBM Corp., Armonk, NY, USA) was used to to analyze the data. The bivariate Pearson correlation was used to determine the validity of the PIDAQ. Cronbach's alpha was used to determine the reliability of the PIDAQ. Further, to determine the reliability of the IOTN-AC, a test-retest was conducted. The Chi-square test was used to determine the association of psychosocial status and orthodontic treatment need. The significance level was set at $5 \%$.

Ethical Aspects

This study obtained ethical approval from the Human Research Ethics Committee of the Faculty of Dentistry of Universitas Indonesia (Protocol No. 010800718).

\section{Results}

The validity test was carried out by a two-tailed test with a significance level of less than 0.05. For each item of the questionnaire statements, the calculated $r$-value is greater than the $r$ table value (0.632). Pearson correlation values obtained from 23 PIDAQ statements have the lowest $r$ count value of 0.653 in PIDAQ number 3, and the highest $r$ count value of 0.946 in PIDAQ numbers 1 and 20. Based on these results, all statements in the questionnaire are valid and can be used in this study. Furthermore, the reliability test was carried out by using Cronbach's Alpha test (0.978).

Table 1 shows that there was a predominance of 16 -year-old students $(78.9 \%)$. 
Table 1. Characteristics of study subjects based on gender and age.

\begin{tabular}{cccc}
\multirow{2}{*}{ Age } & \multicolumn{2}{c}{ Gender } & Total \\
& Boys & Girls & N $(\%)$ \\
\hline 15 Years & $9(9.5)$ & $9(9.5)$ & $18(18.9)$ \\
16 Years & $35(36.8)$ & $40(42.1)$ & $75(78.9)$ \\
17 Years & $1(1.1)$ & $1(1.1)$ & $2(2.1)$ \\
Total & $45(47.4)$ & $50(52.6)$ & $95(100.0)$ \\
\hline
\end{tabular}

Table 2 shows that subjects categorized as having "moderate" psychosocial status based on the PIDAQ have the highest frequency; followed by those having "poor" psychosocial status, that is, a total of 28 subjects (29.5\%); and finally, those having a "good" psychosocial status, that is, a total 21 subjects (of $22.1 \%$ ).

Table 2. Frequency distribution of subjects based on total scores of each component of the PIDAQ.

\begin{tabular}{llc}
\hline Psychosocial Status (Score) & N & $\%$ \\
\hline Good (0-31) & 21 & 22.1 \\
Moderate $(32-61)$ & 46 & 48.4 \\
Poor $(62-92)$ & 28 & 29.5 \\
\hline
\end{tabular}

Table 3 shows that based on the IOTN-AC, subjects who chose picture 6 (Grade 6) have the highest frequency. The data also shows that no one chose picture 10 (Grade 10). The IOTN-AC was grouped into three categories. It was found that subjects with "borderline need for treatment" or "great need for treatment" have the highest frequency. Based on the IOTN-DHC, It is known that subjects with grade 3 have the highest frequency. The IOTN-DHC was grouped into three categories. It was found that subjects with "borderline need for treatment" has the highest frequency.

Table 3. Orthodontic treatment need based on the IOTN-AC and IOTN-DHC.

\begin{tabular}{|c|c|c|c|c|c|c|}
\hline \multirow{3}{*}{ AC Grades } & \multicolumn{2}{|c|}{ IOTN } & \multirow{3}{*}{$\begin{array}{l}\text { Total DHC } \\
\text { N (\%) }\end{array}$} & \multirow{3}{*}{$\begin{array}{c}\text { Orthodontic Treatment } \\
\text { Need }\end{array}$} & \multicolumn{2}{|c|}{ Total IOTN } \\
\hline & Total AC & DHC Grades & & & AC & DHC \\
\hline & $\mathrm{N}(\%)$ & & & & $\mathrm{N}(\%)$ & $\mathrm{N}(\%)$ \\
\hline 1 & $8(8.4)$ & 1 & $7(7.4)$ & No Need For Treatment & $24(25.3)$ & $30(31.6)$ \\
\hline 2 & $6(6.3)$ & & & & & \\
\hline 3 & $7(7.4)$ & 2 & $23(24.2)$ & & & \\
\hline 4 & $3(3.2)$ & & & & & \\
\hline 5 & $19(2.0)$ & 3 & $36(37.9)$ & Borderline Need For Treatment & $47(49.5)$ & $36(37.9)$ \\
\hline 6 & $21(22.1)$ & & & & & \\
\hline 7 & $7(7.4)$ & & & & & \\
\hline 8 & $13(13.7)$ & 4 & $22(23.2)$ & Great Need For Treatment & $24(25.3)$ & $29(30.5)$ \\
\hline 9 & $11(11.6)$ & 5 & $7(7.4)$ & & & \\
\hline
\end{tabular}

There was no statistically significant difference between orthodontic treatment need based on the IOTN-AC and the IOTN-DHC (p=0.303) (Table 4).

Table 4. The difference in orthodontic treatment need based on the IOTN-AC and the IOTN-DHC.

\begin{tabular}{|c|c|c|c|c|c|}
\hline \multirow[b]{2}{*}{$\begin{array}{c}\text { Orthodontic Treatment Need } \\
\text { Based on IOTN-AC }\end{array}$} & \multicolumn{3}{|c|}{ Orthodontic Treatment Need Based on IOTN-DHC } & \multirow[b]{2}{*}{ Total } & \multirow[b]{2}{*}{ p-value* } \\
\hline & $\begin{array}{c}\text { No Need for } \\
\text { Treatment } \\
\text { N (\%) }\end{array}$ & $\begin{array}{c}\text { Borderline Need } \\
\text { for Treatment } \\
\text { N (\%) }\end{array}$ & $\begin{array}{c}\text { Great Need for } \\
\text { Treatment } \\
\mathrm{N}(\%)\end{array}$ & & \\
\hline No Need for Treatment & $8(33.3)$ & $6(25.0)$ & $10(41.7)$ & $24(100.0)$ & 0.303 \\
\hline Borderline Need for Treatment & $12(25.5)$ & $22(46.8)$ & $13(27.7)$ & $47(100.0)$ & \\
\hline Great Need for Treatment & $10(41.7)$ & $8(33.3)$ & $6(25.0)$ & $21(100.0)$ & \\
\hline
\end{tabular}


There was an association between Psychosocial Status based on the PIDAQ and the Orthodontic Treatment Need based on IOTN-AC $(\mathrm{p}<0.001)$ (Table 5)

Table 5 Association between psychosocial status based on the PIDAQ, and orthodontic treatment need based on the IOTN-AC.

\begin{tabular}{|c|c|c|c|c|c|}
\hline \multirow[b]{2}{*}{$\begin{array}{l}\text { Psychosocial Status } \\
\text { Based on PIDAQ }\end{array}$} & \multicolumn{3}{|c|}{ Orthodontic Treatment Need Based on IOTN-AC } & \multirow[b]{2}{*}{ Total } & \multirow[b]{2}{*}{ p-value* } \\
\hline & $\begin{array}{c}\text { No Need for } \\
\text { Treatment } \\
\text { N (\%) }\end{array}$ & $\begin{array}{c}\text { Borderline Need } \\
\text { for Treatment } \\
\mathrm{N}(\%)\end{array}$ & $\begin{array}{c}\text { Great Need for } \\
\text { Treatment } \\
\text { N (\%) }\end{array}$ & & \\
\hline Poor & $6(21.4)$ & $6(21.4)$ & $16(57.1)$ & $28(100.0)$ & $<0.001$ \\
\hline Moderate & $10(21.7)$ & $31(67.4)$ & $5(10.9)$ & 46 (100.0) & \\
\hline Good & $8(38.1)$ & $10(47.6)$ & $3(14.3)$ & $21(100.0)$ & \\
\hline
\end{tabular}

*Chi-Square test; Statistically Significant.

There was no association between Psychosocial Status based on the PIDAQ and the Orthodontic Treatment Need based on the IOTN-DHC $(p=0.140)$ (Table 6).

Table 6. Association between the psychosocial status based on the PIDAQ, and orthodontic treatment need based on the IOTN-DHC.

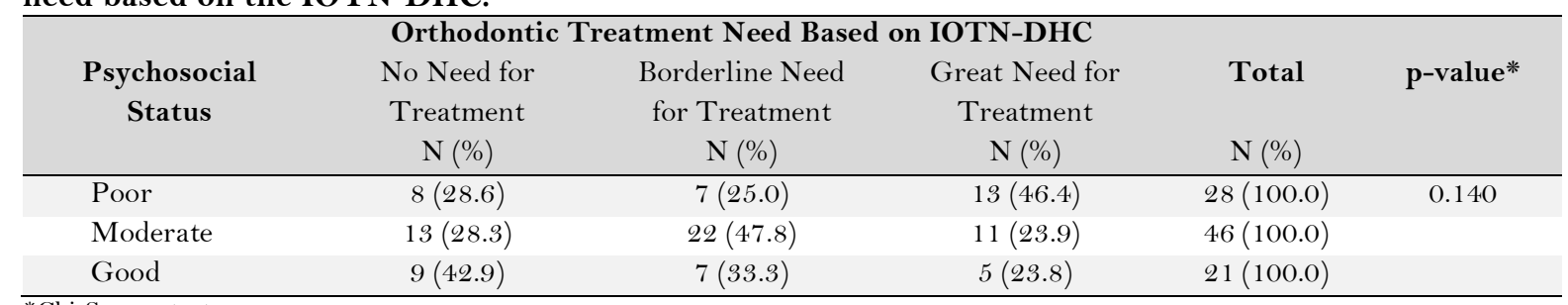

*Chi-Square test.

\section{Discussion}

This study is the first in Indonesia to examine the association between orthodontic treatment needs and the psychosocial status of adolescents. In this study, there is a higher percentage of females than males. The age distribution is dominated by subjects aged 16 years old. This is because of the chosen population, which was 11 th-grade students, and most students in Grade 11 are 16 years old.

In this study, it was found that the psychosocial status of students aged 15-17 years old at SMAN 27 Central Jakarta varied. On the total score of the PIDAQ, the distribution was found highest in the group with moderate psychosocial status. This may occur in accordance with the results of the IOTN-AC and the IOTNDHC, which shows the majority of samples are in the group "borderline need for treatment." Studies conducted in Spain show moderate psychosocial status (total score ranging from 32 to 61) [10,14]. This may occur because both of these studies are carried out with adolescents.

Based on the assessment of IOTN-AC, it is found that the distribution was highest in Grade 6. The IOTN-AC grades are also grouped in accordance with the classification reported by previous authors [16]. The distribution was highest in "borderline need for treatment." This result is in contrast with previous studies, where the majority of the subjects considered themselves to be in the "no need for treatment" group based on the IOTN-AC $[11,14,17]$. Differences in the perception of orthodontic treatment need might be the result of the differences in the geographical location [13]. In addition, the perception of treatment need can be influenced by the age of the sample [18]. The difference can be attributed to cultural differences in the population [19]. 
Based on the examination of teeth, done with the help of an IOTN disposable ruler, the distribution was found highest in Grade 3. The IOTN-DHC grades are also grouped based on the classification previously described [16]. It is found that the distribution was highest in "borderline need for treatment." The distribution found by other authors [20], is similar to that of the present study, which is "borderline need for treatment”. However, these results contradict findings from previous study, in which the highest distribution was "no need for treatment" [21]. This difference can be caused by levels of malocclusion that are different in each population. The difference in results might be because of the difference in the number of samples studied [19].

The unpaired categorical comparative analytic test was conducted on two variables, which are orthodontic treatment need based on the IOTN-AC, completed by the subjects subjectively, and orthodontic treatment need based on the IOTN-DHC, assessed by the researcher objectively. Based on the results of the chi-square test, there is no statistically significant difference in orthodontic treatment need, which was obtained from the assessment of the IOTN-AC and the IOTN-DHC. Previous studies showed no association between the IOTN-AC and the DHC [17,22,23]. Although there is no statistically significant difference, the total number of subjects in each level of treatment needs based on the IOTN-DHC differs from the total number of subjects on the level of treatment need based on the IOTN-AC. It can be concluded that there are considerable differences between professionals' and patients' perceptions of the level of malocclusion. This result is in accordance with other authors' studies that found a difference in the number of subjects in need of orthodontic treatment subjectively by patients and objectively by the dentist [21]. This may be caused by the lack of education given to the patient so that there is a failure in identifying and evaluating abnormal conditions of the teeth [21]. Differences between the components of the AC and the DHC may be due to certain conditions of the teeth, such as crowding in the lower jaw, large overjet, missing posterior teeth, and canines that are not visible in the photos shown in the IOTN-AC [17].

The unpaired categorical comparative analytic test was conducted on two other variables, which are psychosocial status based on the PIDAQ and orthodontic treatment need based on the IOTN-AC. From the results of the Chi-Square test, it can be concluded that there is a relationship (association) between the psychosocial status based on the PIDAQ and orthodontic treatment need based on the IOTN-AC and this is in agreement with the previous results [24]. Based on data obtained, the higher the need for orthodontic treatment based on the self-perception of subjects, the worse the psychosocial status of the subjects. This may occur because dental aesthetics influence the quality of life of the respondents. Facial appearance also has a very great influence on the mental condition, in particular, self-confidence, which is one of the aspects of the psychosocial domain [25].

The unpaired categorical comparative analytic test was conducted on two other variables, which are psychosocial status based on the PIDAQ and orthodontic treatment need based on the IOTN-DHC. From the results of the chi-square test, it can be concluded there is no relationship (association) between psychosocial status based on the PIDAQ and orthodontic treatment need based on the IOTN-DHC and this is in contrast to previous findings [26]. Although there are no statistically significant differences between two variables, it is found that the highest distribution of subjects with "great need for treatment" is found in the "poor" psychosocial status group, the highest distribution subjects with "borderline need for treatment” is found in the "moderate" psychosocial status group, and the highest distribution subjects with "no need for treatment" is found in the "good" psychosocial status group. The psychosocial impact obtained from dental aesthetic increases in line with the severity of malocclusion, based on the assessment of the IOTN-DHC [26,27]. 
Further research is expected to determine the strength of the relation between psychosocial status and orthodontic treatment need in Indonesia. Future research can also be carried out using a larger sample covering a wider area and using other factors that have not been studied, such as age and level of education. The IOTN and the PIDAQ can also be extended to various regions in Indonesia to determine whether or not socio-cultural and racial factors affect the results.

In addition, in clinical practice, the assessment should be based not only on an objective assessment of the dentist, but the patient's participation in determining orthodontic treatment using the IOTN-AC to determine the patient's perception of dental aesthetics so that the patient is satisfied with the treatment. However, considering that the IOTN-AC does not include a picture of class III malocclusion, it is necessary to have an index that assesses individual perceptions of orthodontic treatment needs, which includes a picture of class III malocclusion, in order to reduce bias.

\section{Conclusion}

In this study, "moderate" psychosocial status and "borderline need for treatment" group has the highest distribution. There is no statistically significant difference between orthodontic treatment need based on subjective assessment (IOTN-AC) and objective assessment (IOTN-DHC). There is an association between psychosocial status and orthodontic treatment need based on subjective assessment. However, conversely, there is no association between psychosocial status and orthodontic treatment need based on objective assessment.

At SMAN 27 Jakarta, it was found that many teenagers were still not aware of malocclusion and its effects, so it was necessary to add materials about malocclusion in dental and oral health counseling conducted with school-age children to prevent future negative effects of malocclusion. In addition, counseling on dental and oral health needs to be done at other schools in order to prevent negative functional and psychosocial impacts from the condition of malocclusion. However, given the large number of students who have been affected by malocclusion, there is a need for further treatment so that the negative impact caused by malocclusion can be arrested.

\section{Authors' Contributions}

\begin{tabular}{|c|c|c|}
\hline CNS & (iD) $0000-0002-2083-4630$ & Investigation, Formal Analysis and Writing - Original Draft Preparation. \\
\hline $\mathrm{FJ}$ & (iD) $0000-0001-8577-1485$ & Conceptualization, Methodology, Supervision and Writing - Review and Editing. \\
\hline NI & (iD) 0000-0003-072 1-8005 & $\begin{array}{l}\text { Conceptualization, Formal Analysis, Supervision and Writing - Review and } \\
\text { Editing. }\end{array}$ \\
\hline
\end{tabular}

\section{Financial Support}

HIBAH PITTA B Research Grant from Universitas Indonesia (Grant No: NKB 0572/UN2.R3.1/HKP.05.00/2019).

\section{Conflict of Interest}

The authors declare no conflicts of interest.

\section{References}

[1] Afroz S, Rathi S, Rajput G, Rahman SA. Dental esthetics and its impacto n psycho-social well-being and dental sef confidence: A cmapus based survey of north Indian university students. J Indian Prosthodont Soc 2013; 13(4):455-60. https://doi.org/10.1007/s13191-012-0247-1 
[2] Bittencourt MAV, Machado AW. An overview of the prevalence of malocclusion in 6 to 10-year-old children in Brazil. Dent Press J Orthod 2010; 15(6)113-22. https://doi.org/10.1590/S2 176-94512010000600015

[3] Tang X, Cai J, Lin B, Yao L, Lin F. Motivation of adult female patientes seeking orthodontic treatment: an application of q- methodology. Patient Prefer Adherence 2015; 9:249-56. https://doi.org/10.2 147/PPA.S78691

[4] Proffit WR, Fields HW. Contemporary Orthodontics. 5th ed. St. Louis: Mosby Elsevier; 2013.

[5] Samsonyanová L, Broukal Z. A systematic review of individual motivational factors in orthodontic treatment: facial attractiveness as the main motivational fator in orthodontic treatment. Int $\mathrm{J}$ Dent 2014; 2014:938274. https://doi.org/10.1155/2014/938274

[6] Klages U, Claus N, Wehrbein H, Zentner A. Development of a questionnaire for assessment of the psychosocial impact of dental aesthetics in young adults. Eur J Orthod 2006; 28(2):103-11. https://doi.org/10.1093/ejo/cjio83

[7] Sanders RA. Adolescent psychosocial, social, and cognitive development. Pediatr Rev 2013; 34(8):354-8. https://doi.org/10.1542/pir.34-8-354

[8] Topp CW, Østergaard SD, Søndergaard S, Bech P. Thw WHO-5 well-being index: a systematic review of the literature. Psychother Psychosom 2015; 84(3):167-76. https://doi.org/10.1159/000376585

[9] Endicott J, Spitzer RL, Fleiss JL, Cohen J. The global assessment scale. A procedure for measuring overall severity of $\begin{array}{lllll}\text { psychiatric } \quad \text { disturbance. } & \text { Arch }\end{array}$ https://doi.org/10.1001/archpsyc.1976.01770060086012

[10] Bellot-Arcís C, Montiel-Company JM, Almerich-Silla JM. Psychosocial impact of malocclusion in Spanish adolescents. Korean J Orthod 2013; 43(4);193-200. https://doi.org/10.4041/kjod.2013.43.4.193

[11] Aikins EA, Dacosta OO, Onyeaso CO, Isiekwe MC. Self-perception of malocclusion among Nigerian adolescentes using the aesthetic componente of the IOTN. Open Dent J 2012; 6:61-6. https://doi.org/10.2174/1874210601206010061

[12] Livas C, Delli K. Subjetive and objective perception of orthodontic treatment need: a systematic review. Eur J Orthod 2013; 35(3):347-53. https://doi.org/10.1093/ejo/cjr142

[13] Josefsson E, Bjerklin K, Lindsten R. Factors determining perceived orthodontic treatment need in adolescents of Swedish and immigrant background. Eur J Orthod 2009; 31(1):95-102. https://doi.org/10.1093/ejo/cjno69

[14] Fox D, Kay EJ, O'Brien K. A new method of measuring how much anterior tooth alignment means to adolescents. Eur J Orthod 2000; 22(3):299-305. https://doi.org/10.1093/ejo/22.3.299

[15] Ravindranath S, En JTS, Heng APK. Orthodontic treatment need and self-perceived psychosocial impact of dental esthetics in a university adult population in Malaysia. J Indian Orthod Soc 2019; 51(2):69-74. https://doi.org/10.4103/jios.jios_214_16

[16] Shaw WC, Richmond S, O'Brien KD. The use of occlusal indices: a European perspective. Am J Orthod Dentofacial Orthop 1995; 107(1):1-10. https://doi.org/10.1016/s0889-5406(95)70151-6

[17] Singh N, Bagga D, Sharma R, Singh R. Evaluation of reliability of index of orthodontic treatment need for assessment of orthodontic treatment need. Int J Orthod Rehabil 2017; 8(1):5-10. https://doi.org/10.4103/2349-5243.200224

[18] Fariba S, Sirous R. Use of the Index of orthodontic treatment need in a school population Zahedan. Life Sci J 2013; $10(2 s): 240-4$.

[19] Marzaki Moghadam M, Moghimbeigi A, Jafari F. Evaluation of orthodontic treatment needs in a population of Iranian schoolchildren using the IOTN in 2010. DJH 2011; 3(2):35-43.

[20] Sharma J, Sharma RD. IOTN - A tool to prioritize treatment need in children and plan dental health services. Oral Health Dent Manag 2014; 13(1):65-70.

[21] Padisar P, Naseh R, Babakhani A, Jalayer S. Comparing Dental Aesthetic Index (DAI) and IOTN in determining the orthodontic treatment needs of Qazvin students. Iran J Orthod 2016; 11(2):e6231.

[22] Alatrach AB, Saleh FK, Osman E. the prevalence of malocclusion and orthodontic treatment need in a sample of Syrian children. Eur Sci J 2014; 10(30):230-47.

[23] Hedayati Z, Fattahi HR, Jahromi SB. The use of index of orthodontic treatment need in an Iranian population. J Indian Soc Pedod Prev Dent 2007; 25(1):10-4. https://doi.org/10.4103/0970-4388.31982

[24] Wan Hassan NW, Yusof ZYM, Shahidan SSZ, Mohd Ali SF, Makhbul MZM. Validation and reliability of the translated malay version of the psychosocial impact of dental aesthetics questionnaire for adolescents. Health Qual Life Outcomes 2017; 15(1):23. https://doi.org/10.1186/s12955-017-0600-5

[25] Lin F, Ren M, Yao L, He Y, Guo J, Ye Q. Psychosocial impact of dental esthetics regulates motivation to seek orthodontic treatment. Am J Orthod Dentofacial Orthop 2016; 150(3):476-82. https://doi.org/10.1016/j.ajodo.2016.02.024

[26] Hassan AH, Amin HES. Association of orthodontic treatment needs and oral health-related quality of life in young adults. Am J Orthod Dentofacial Orthop 2010; 137(1):42-7. https://doi.org/10.1016/j.ajodo.2008.02.024.

[27] Yi S, Zhang C, Ni C, Qian Y, Zhang J. Psychosocial impact of dental aesthetics and desire for orthodontic treatment among Chinese undergraduate students. Patient Prefer Adherence 2016; 10:1047-42. https://doi.org/10.2147/PPA.S105260 